EMBRYARIDDLE
Aeronautical University

SCHOLARLY COMMONS
International Journal of Aviation, Aeronautics, and Aerospace

\title{
Aerodynamic characterization of bio-mimicked pleated dragonfly aerofoil
}

\author{
Md Akhtar Khan \\ GITAM University, khan.akhtar24@gmail.com \\ Chinmaya Padhy \\ GITAM University, dr.padhy.iitkgp@gmail.com
}

Follow this and additional works at: https://commons.erau.edu/ijaaa

Part of the Aerodynamics and Fluid Mechanics Commons

\section{Scholarly Commons Citation}

Khan, M. A., \& Padhy, C. (2021). Aerodynamic characterization of bio-mimicked pleated dragonfly aerofoil. International Journal of Aviation, Aeronautics, and Aerospace, 8(2). https://doi.org/10.15394/ ijaaa.2021.1562

This Article is brought to you for free and open access by the Journals at Scholarly Commons. It has been accepted for inclusion in International Journal of Aviation, Aeronautics, and Aerospace by an authorized administrator of Scholarly Commons. For more information, please contact commons@erau.edu. 


\section{Aerodynamic characterization of bio-mimicked pleated dragonfly aerofoil}

\section{Cover Page Footnote}

We are grateful to GITAM University for providing the Computational Simulation facility for doing this research work more effectively. 
The dragonfly is the source of inspiration for scientists and engineers to understand the mechanical behaviour of low Reynolds number flyers. Several studies reveal that the dragonfly forewing reveals a highly corrugated structure that helps to develop the most suitable Bio-mimetic micro air vehicles (BMAVs) and implement new technology to develop futuristic wing shape and design (Fish, 2006; Hu \& Tamai, 2008; Norberg, 1975; Wakeling \& Ellington,1997.)

The agility of dragonfly's gliding flight allows them to dip and dart in any direction, elevating up to an altitude of $100 \mathrm{~m}$ into the air. The earlier investigation also showed that flapping corrugated flight's lift coefficient exceeds the steady level flight (SLF) of non- flapping insects (Levey, 2009; Murphy \& Hu, 2010). Thus, this feathery and non-smooth wing features shown to be the cause of improved performance (Khan, 2021; Lu \& Lan, 2013) by delaying flow separation and stall at high AoA (angle of attack), is most desirable advantage into bio-mimetic MAVs.

In addition, past computational studies (Rees, 1975a; Vargas, 2006; Zhou, 2013) related that the corrugated wing produces higher lift and less drag. The dragonfly wing experiences a significant amount of bending and twisting during flight, which will change the aerodynamics and structural response during loading conditions. The geometry used in this study taken from the sub-costa part of the dragonfly wing which lies at $40 \%$ of the total span in the chordwise direction from the root of the forewing as shown in Figure 1. The wing cross-section around the mid-span has various corrugated structures which amplify the performance of the dragonfly.

Usually, insect wings are considered as a flat pleated shape in various studies of flight performance for MAVs (Gao \& Hu, 2008; Kesel, 2000; Mingallon \& Ramaswamy, 2011). In case of dragonfly, with a pleated corrugated structure, wings are composed of the membrane set in the form of $\mathrm{V}$-shaped valleys (Barnes, 2013; Okamoto, 1996; Vargas, 2008). Numerous studies asserted that the kind of mechanism and exemplary smart structure of dragonfly wing can withstand an array of loads and their combination due to high stability and skinny waxy layer covering consists of chitin and structural proteins (Ho \& New, 2016; Khan, 2020; Menter, 2012; Taylor, 2003).

This work was inspired by the dragonfly wing corrugation located at the radius part of the branch, nearly $40 \%$ of the wing's total span from the root. During gliding flight, dragonfly wings are considered ultra-light aerofoil due to its welldefined cross-sectional corrugation. A number of researchers, including Broering (2012), Khan (2020), and Padhy and Khan (2018), have investigated the aerodynamic benefits. Still, few have investigated the free vibration behaviour of 
the dragonfly corrugated aerofoil and mode shape of the corrugated aerofoil (Tamai, 2007).

\section{Figure 1}

Pleated Corrugated Aerofoil at $40 \%$ From the Root of the Forewing

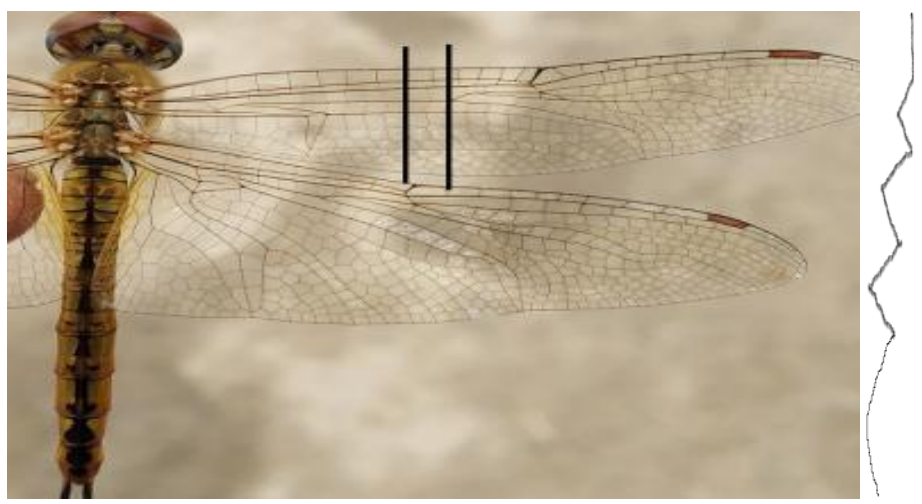

\section{Methodology Geometric Modeling}

The rigid two-dimensional corrugated Profile and traditional aerofoil NACA 0015 is modelled in CATIA V5, as shown in Figure 2. The span is considered as a unity, and the chord length is $110 \mathrm{~mm}$ with $4 \mathrm{~mm}$ thickness. However, a study by Chen and Skote (2016) confirmed that the chordwise variation in the cross-sectional area has significant importance.

\section{Figure 2}

CATIA Design of Corrugated and NACA 0015 Aerofoil

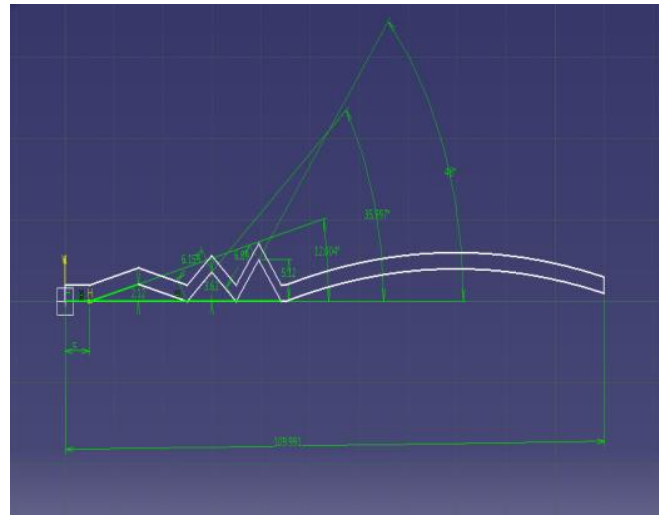

(a)Pleated corrugated aerofoil

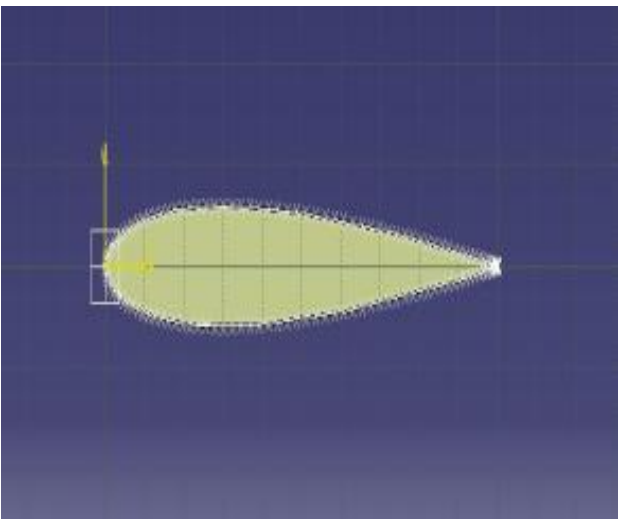

(b) NACA 0015 


\section{Grid Generation}

A grid framework is used to maintain a high proximity measure, and wellmaintained aspect ratio cell sizes. A circular computational domain is created for the corrugated Profile and C-computational domain for the conventional aerofoil with orthogonality of 0.50 . For CFD analysis at inlet portion, velocity components were set, and the uniform condition is used throughout the surface. The pressure is equal to free-stream static pressure at the outlet, and on the aerofoil surface, the noslip boundary condition is contemplated. The computational mesh or grid cell is nearly between $4 \times 10^{5}$ to $5 \times 10^{5}$, and the mesh view is shown in Figure 3(a) Computational grid of corrugated Profile (b) Computational grid of NACA 0015.

\section{Figure 3}

Computational Grid of Corrugated Aerofoil and NACA 0015

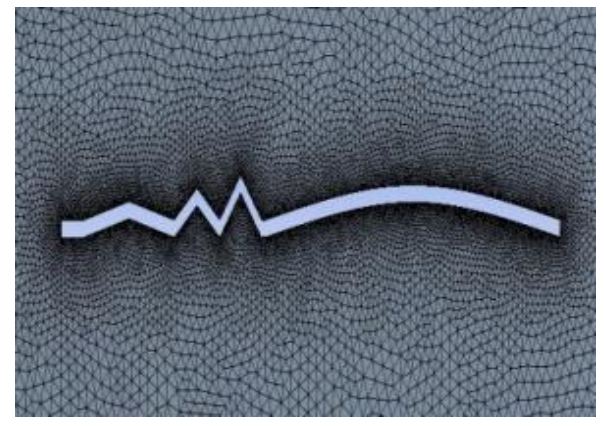

(a) Mesh Close-up view

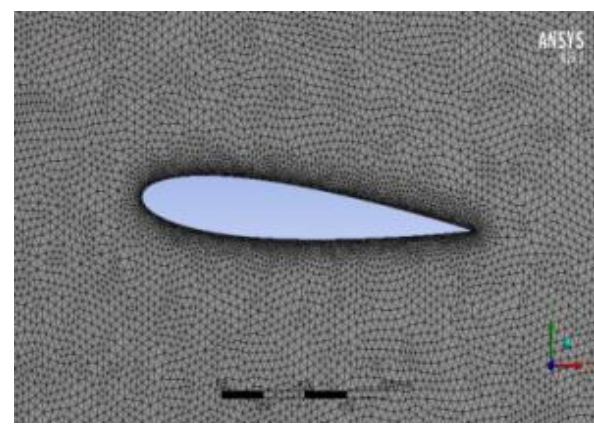

(b) Extended view

\section{CFD Simulation Results}

Two dimensional CFD simulation carried out to know the flow behaviour and aerodynamic characteristics of the pleated and profiled aerofoil. The main aim is to calculate the spatial aerodynamic lift and drag and their coefficients. The highfidelity model is used to figure out the importance of corrugation on the low Reynolds number MAVs flyer performance having corrugated wing. The simulation performed at different angle of attack varying from $0^{\circ}$ to $12^{\circ}$ at two distant velocities of $10 \mathrm{~m} / \mathrm{s}$ and $15 \mathrm{~m} / \mathrm{s}$.

\section{At 0-degrees AoA and $10 \mathrm{~m} / \mathrm{s}$ velocity}

In this case, we have performed CFD analysis at 0 degrees AoA and a velocity of $10 \mathrm{~m} / \mathrm{s}$, i.e., $\mathrm{Re}=75000$ to calculate the aerodynamic performance parameters and understand the flow behaviour pleated and traditional aerofoil. 


\section{Figure 4}

CFD Results at $A o A=0$ (degree $)(\operatorname{Re}=75000)$
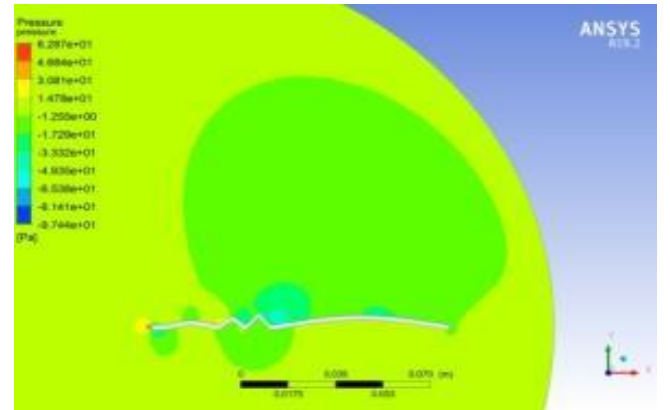

(a) Pressure contour of corrugated Profile

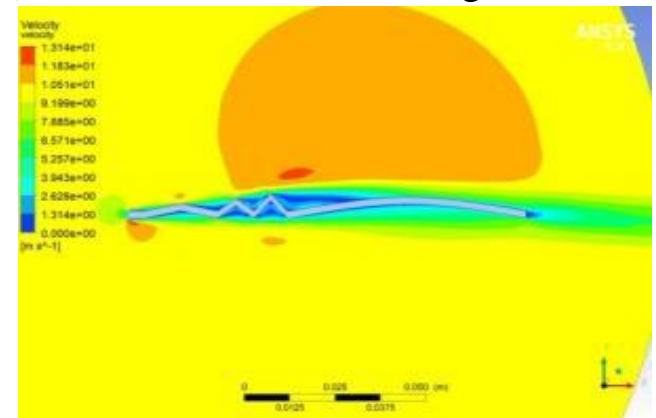

(c) Velocity contour of corrugated Profile

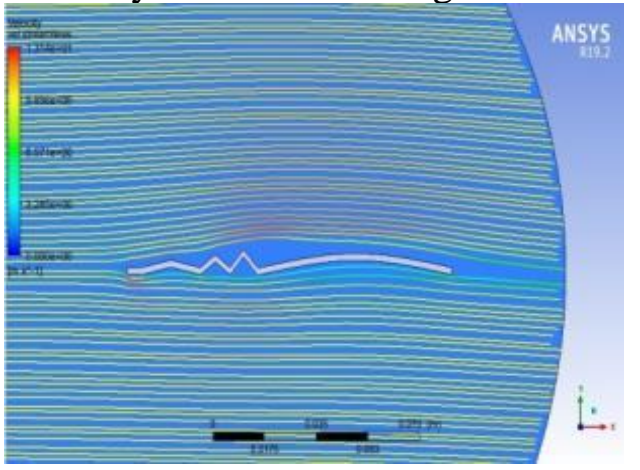

(e) Streamline of corrugated Profile

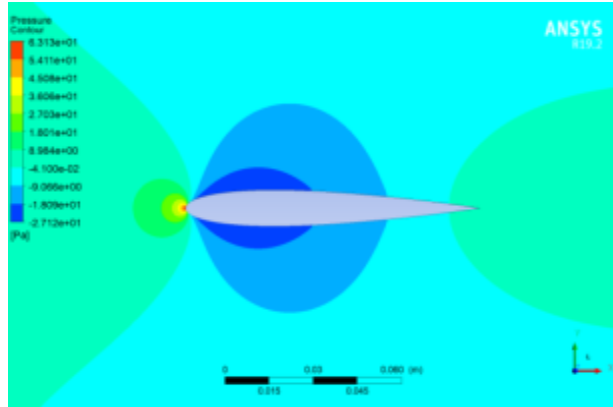

(b) Pressure contour of NACA 0015

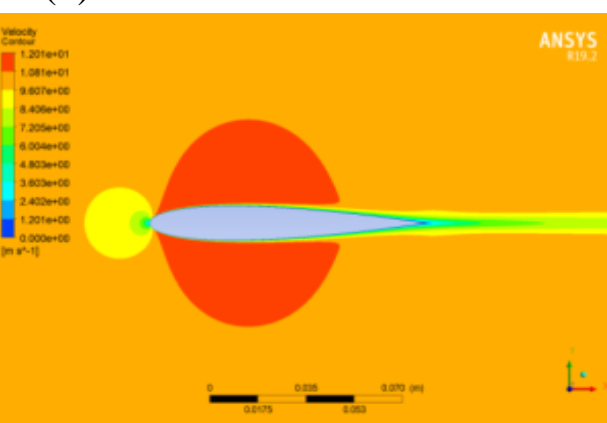

(d) Velocity contour of NACA 0015

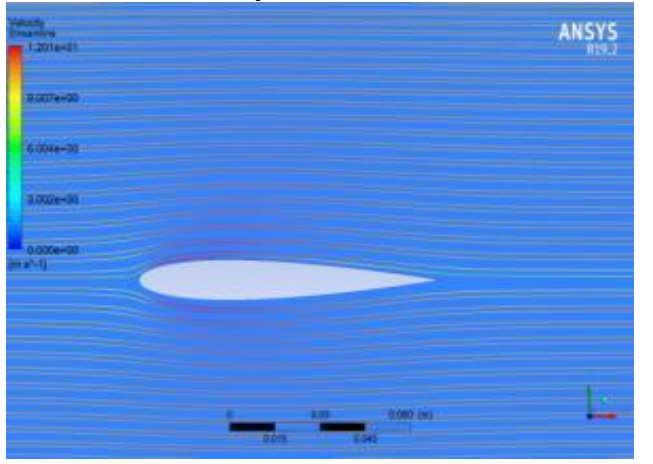

(f) Streamline of NACA 0015 


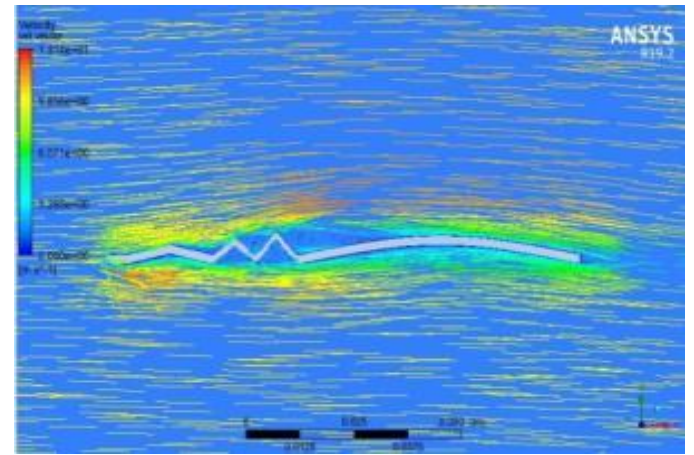

(g) Velocity vector of corrugated Profile

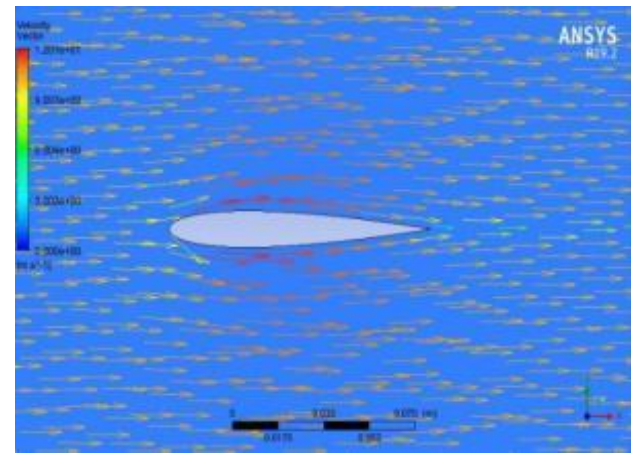

(h)Velocity vector of NACA 0015

All the essential aerodynamic parameters are analyzed at 0 degrees AoA as shown in Figure 4. Figure 4(a) shows that the pressure distribution is high at the stagnation points. Simultaneously velocity is zero at that stagnation point because the pressure is inversely proportional to velocity as shown in Figure 4(c) and pressure is low at the peak of the pleated aerofoil, as there is high velocity on the upper surface. Also, at the grooves, the adverse pressure gradient is indicating reversed flow. Since in Figure 4(b) shows that the pressure is maximum for NACA 0015 at the leading edge, it is low compared to the pleated corrugated aerofoil.

Figure 4(g) shows that the velocity vector diagram relates the flow's streamline pattern, and the vortices are trapped inside the valley of corrugated aerofoil and delays separation. In contrast, for conventional aerofoil, the flow passes smoothly over the surface. Figure 5 shows the variant of the force coefficient concerning the time iterative process. 


\section{Figure 5}

Aerodynamic Performance Parameters with respect to Iteration at $A 0 A=0$ degree

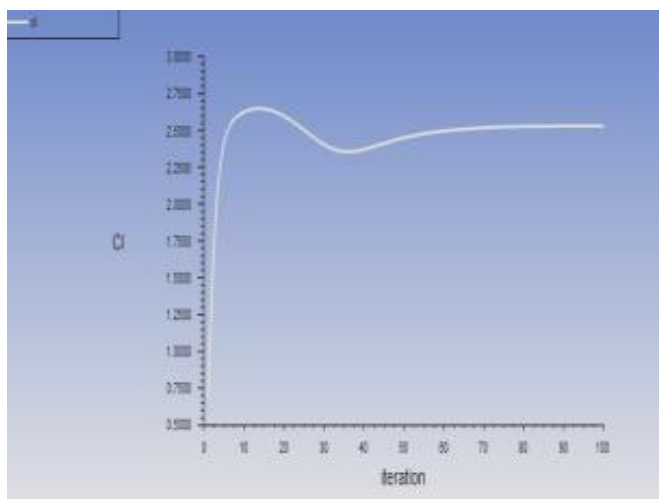

(a) $C_{1}$ of corrugated pleated Profile

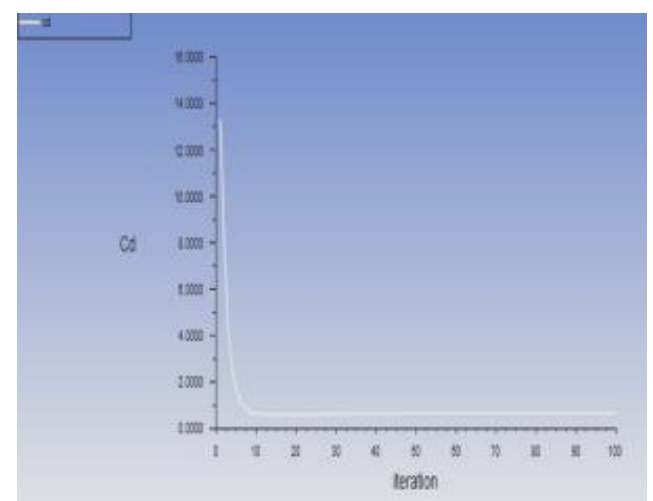

(c) $C_{d}$ of corrugated pleated profile

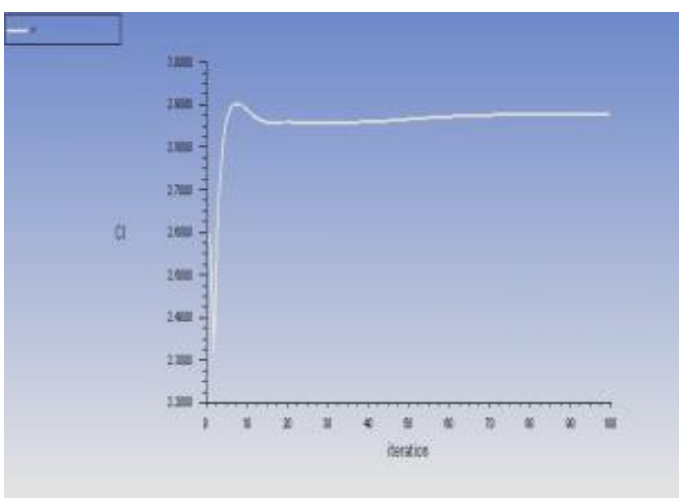

(b) $\mathrm{C}_{1}$ of NACA 0015

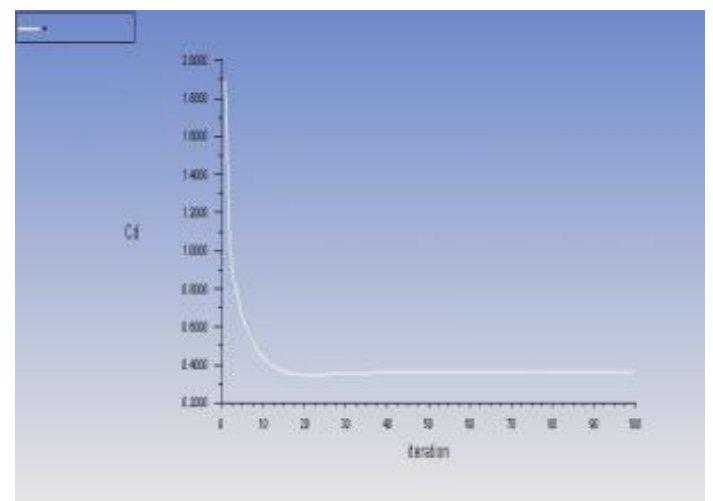

(d) $\mathrm{C}_{\mathrm{d}}$ of NACA 0015

\section{At 4-degrees AoA and $10 \mathrm{~m} / \mathrm{s}$ velocity}

The AoA is increased from 0 degrees to 4 degrees to observe the variation in the flow behaviour and change in the aerodynamic performance over the corrugated aerofoil and profiled aerofoil with increment in angle of attack. 
Figure 6

CFD Results at $A o A=4($ degree $)(\operatorname{Re}=75000)$

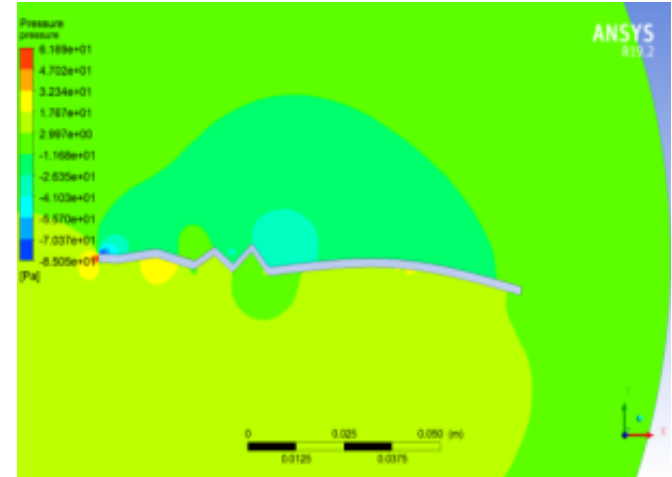

(a)Pressure plot of corrugated Profile

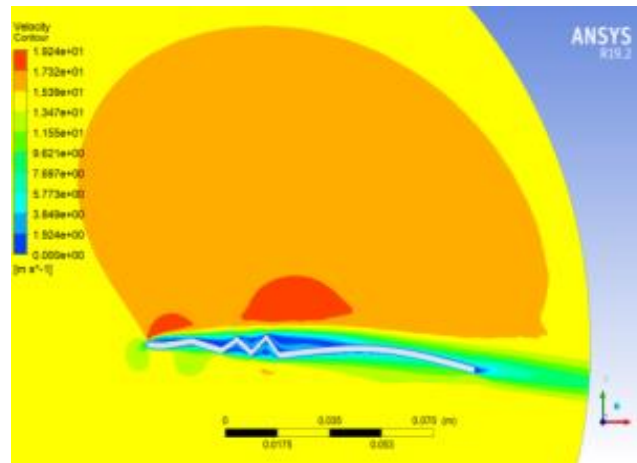

(c) Velocity plot of corrugated Profile

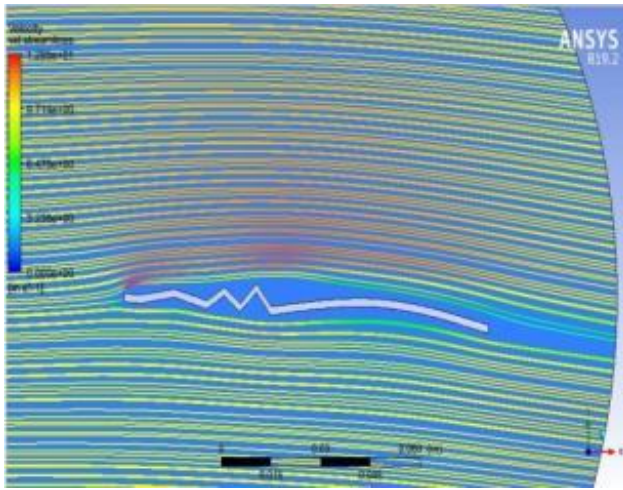

(e) Streamline of Corrugated aerofoil

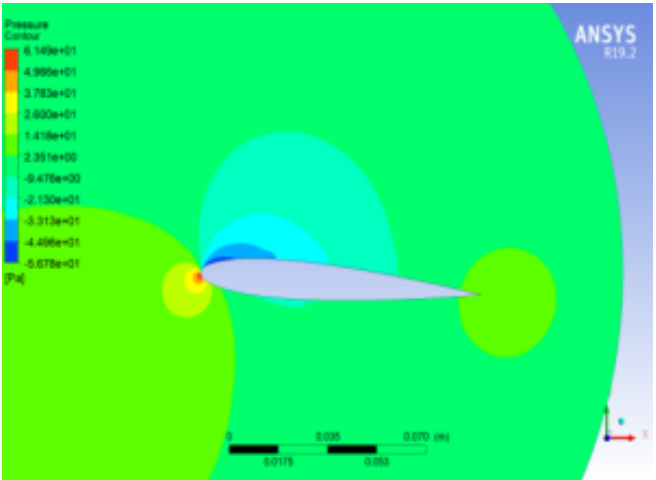

(b)Pressure plot of NACA 0015

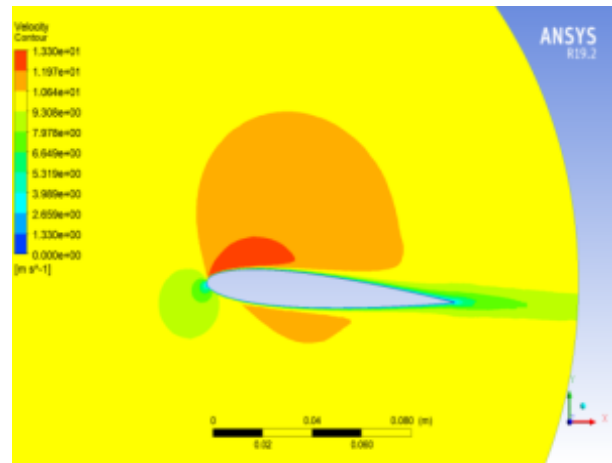

(d) Velocity plot of NACA 0015

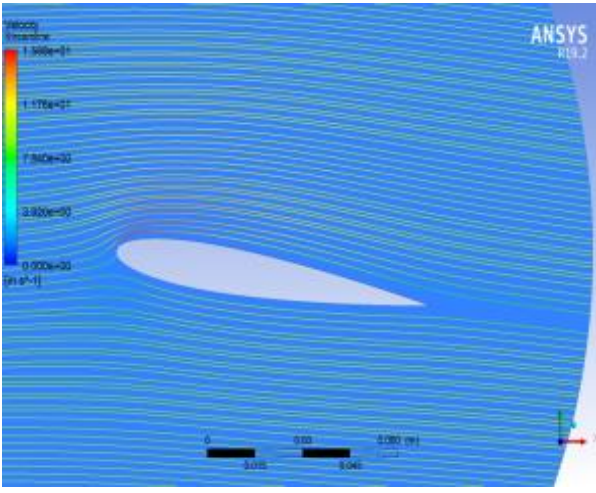

(f) Streamline of NACA 0015 


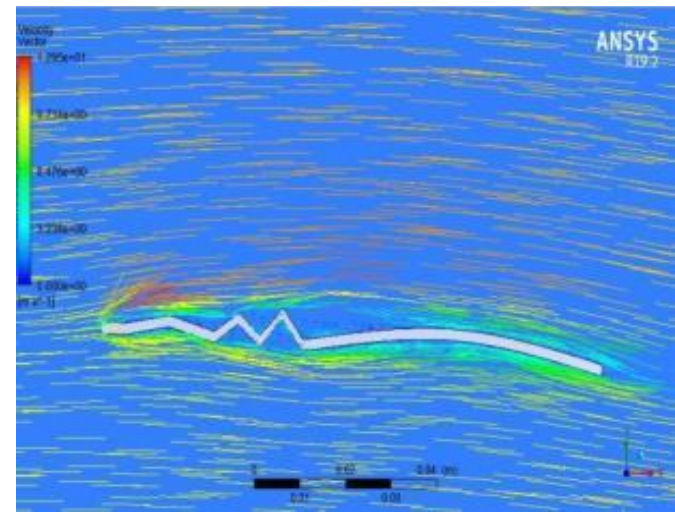

(g) Velocity vector of corrugated Profile

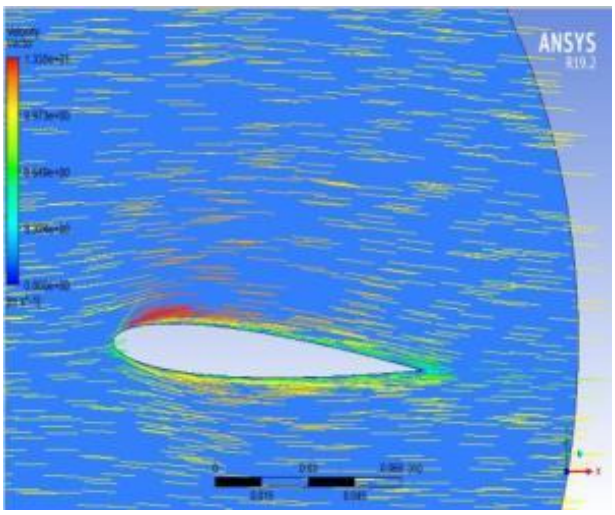

(h) Velocity vector of NACA 0015

As shown in Figure 6(a) at 4 degrees AoA, i.e., with the increase in incidence from 0 degrees to 4 degrees, the pressure on the lower surface of corrugation increases and on the top decreases as the progressive flow on the crest is higher implies the increase in lift. As lift increases, $\mathrm{C}_{\mathrm{L}}$ also increases, resulting in an increment of L/D ratio, which reduces the eddies and vortices. The vortices are trapped inside the valley and reattaches to the surface or peak delaying flow separation. Figure 6(b) indicates the pressure variation on the profiled counterpart.

Figure $6(\mathrm{~g})$ showcases the flow is separating at the front edge of the corrugated aerofoil, leading to circulation, but as we can see because of pleated design, i.e., in the valleys and peak reversed flow occurs. The flow tries to reattach to the top facade and leaves the rearmost edge smoothly. As the incidence angle increases from 0 degrees to 4 degrees, the stagnation point starts shifting to the bottom of the corrugation front edge and pressure at the front crest is maximum where the velocity is zero exhibits in Figure 6(c) and 6(d). The performance iteration curves are shown in Figure7. 


\section{Figure 7}

Aerodynamic Performance Parameters with respect to Iteration at $\mathrm{A} 0 \mathrm{~A}=0^{\circ}$

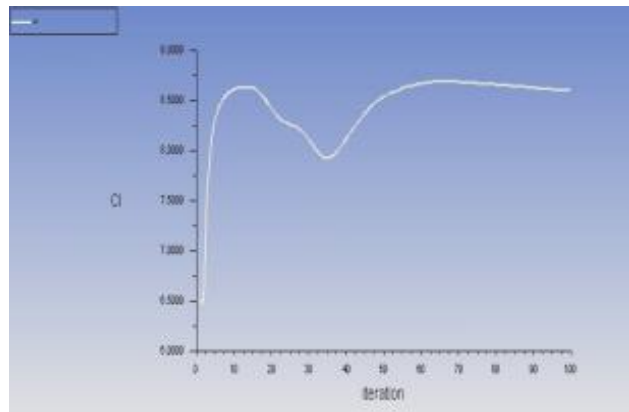

(a) $\mathrm{C}_{1}$ of corrugated Profile

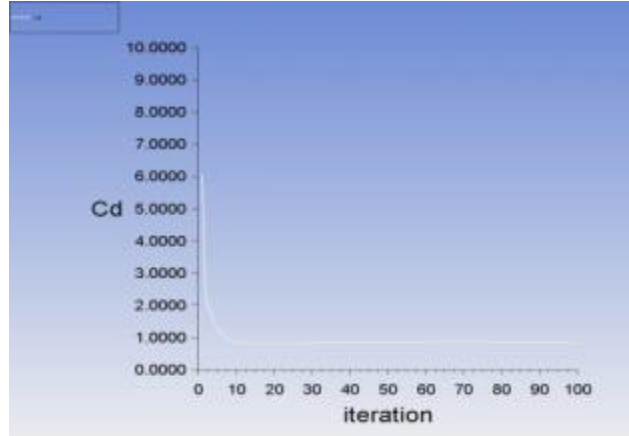

(c) $\mathrm{C}_{\mathrm{d}}$ of corrugated profile

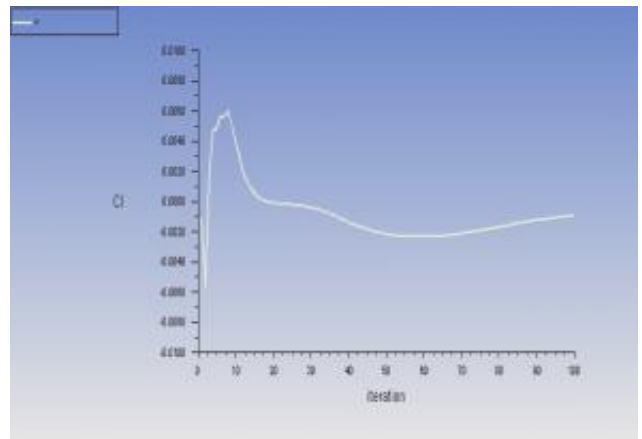

(b) $\mathrm{C}_{1}$ of NACA 0015

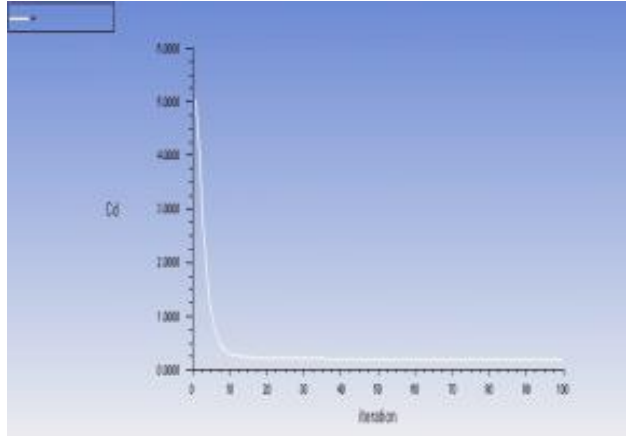

(d) C $_{d}$ of NACA 0015

\section{At 8 degrees AoA and $10 \mathrm{~m} / \mathrm{s}$ velocity}

As the angle is increased from 4 degrees to 8 degrees, we observed that the variation in the flow behaviour over the corrugated aerofoil and profiled aerofoil changed a lot and the flow separation started occurring at the leading edge of the NACA 0015, and the lift starts falling from this point for the conventional aerofoil at low Reynolds number. 


\section{Figure 8}

CFD Results at $A o A=8($ degree $)(R e=75000)$

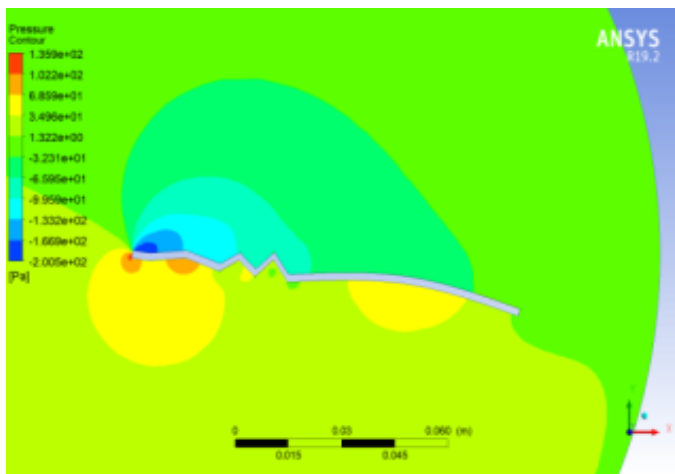

(a)Pressure plot of corrugated Profile

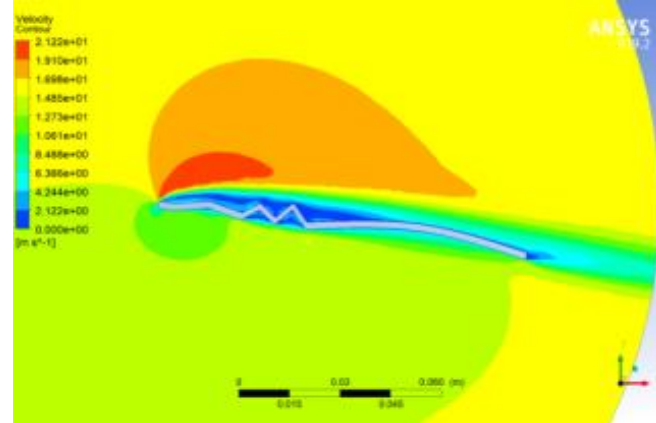

(c) Velocity plot of corrugated Profile

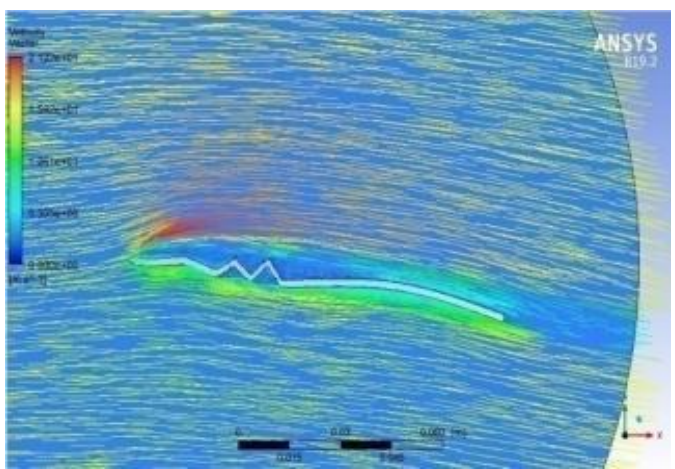

(e) Velocity vector of the corrugated profile

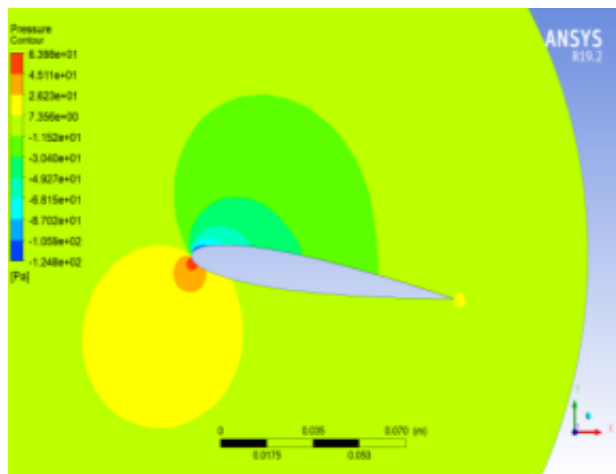

(b) Pressure plot of NACA 0015

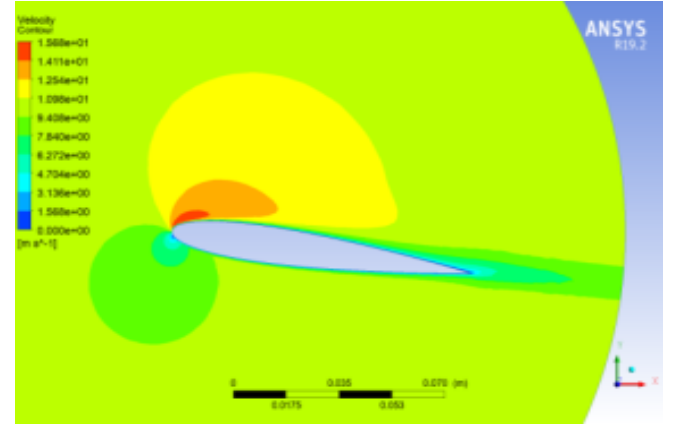

(d) Velocity plot of NACA 0015

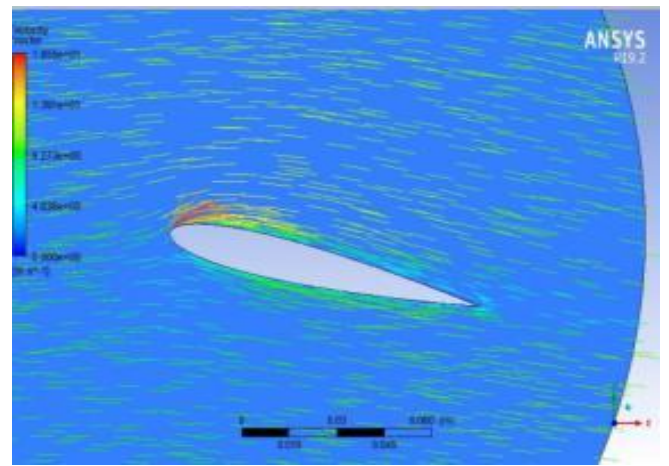

(f) Velocity vector of NACA 0015

The red dot represents the stagnation point where pressure is higher on the lower part of the wing, which implies velocity is lower on the sub-surface and higher velocity on the top side which results in pressure difference, resulting in the 
production of lift as shown in Figures 8(a) and 8(b). But we can observe that in Figures 8(c) and 8(d) the flow separation started in pleated as-well-as in the conventional aerofoil. Since high velocity on the facade and zero velocity in the rift indicate reversed flow due to adverse pressure gradient, vortices formation is shown in Figures 8(e) and 8(f). Here, the flow is trying to reattach on the corrugated counterpart compared to NACA 0015 aerofoil. The lower surface flow re-energizes the upper surface flow delaying flow separation, which gives better L/D ratio. We know that higher corrugation angle delays the flow separation by ensuring better $\mathrm{L} / \mathrm{D}$ ratio.

\section{Figure 9}

CFD Results at $A o A=12($ degree $)(\operatorname{Re}=75000)$

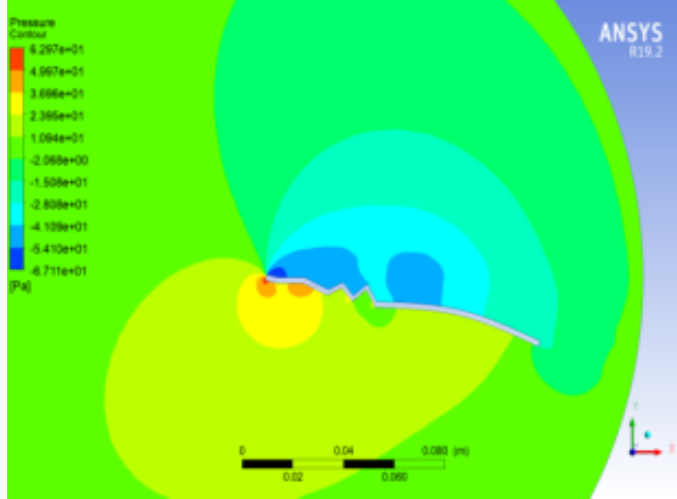

(a)Pressure plot of corrugated Profile

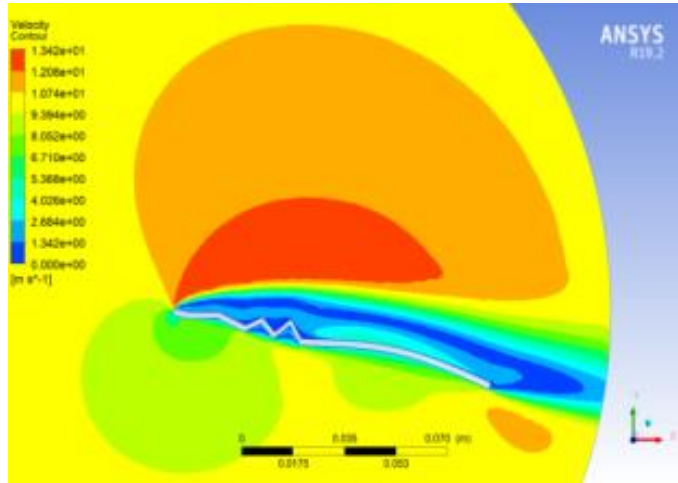

(c) Velocity plot of corrugated profile

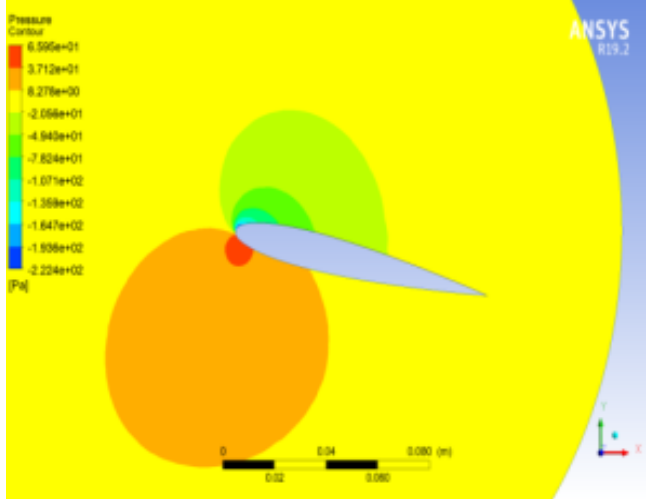

(b) Pressure plot of NACA 0015

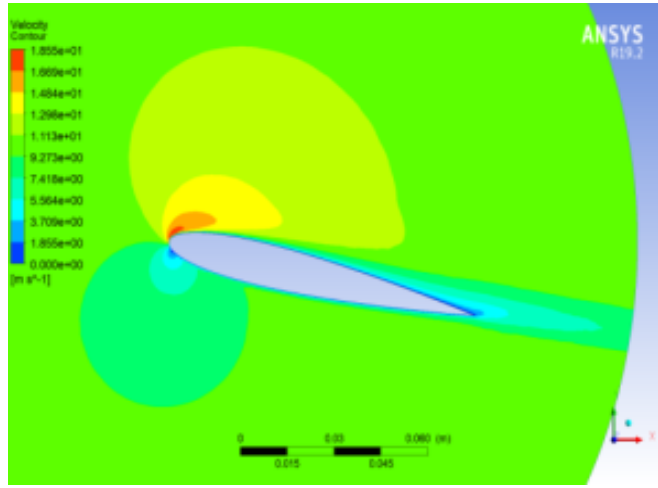

(d) Velocity plot of NACA 0015 


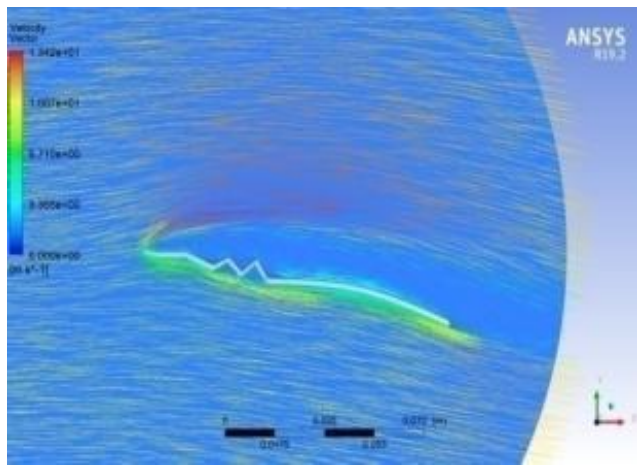

(e) Velocity vector of corrugated profile

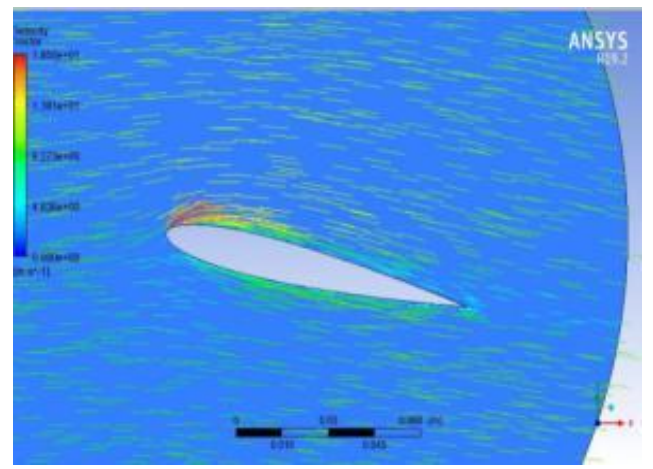

(f) Velocity vector of NACA 0015

\section{At 12-degrees AoA and $10 \mathrm{~m} / \mathrm{s}$ velocity}

As shown in Figure 9, By increasing angle of attack we understood that as the drift angle (AoA) increases the performance of corrugation is more effective, i.e., the L/D ratio goes on increasing as compared to the profiled aerofoil, the segregation and transition point shift on the upside surface. Due to the design features the stall is delayed, and the reversed flow reattaches on the upper surface and leaves the rear edge smoothly without any disturbance as shown in Figure 9(e) which is not possible in case of flow over the traditional aerofoil as shown in Figure 9(f). Figure 10 represents the iterative curve of performance coefficients.

\section{Figure 10}

Aerodynamic Performance Parameters with respect to Iteration at AoA $=12$ degrees

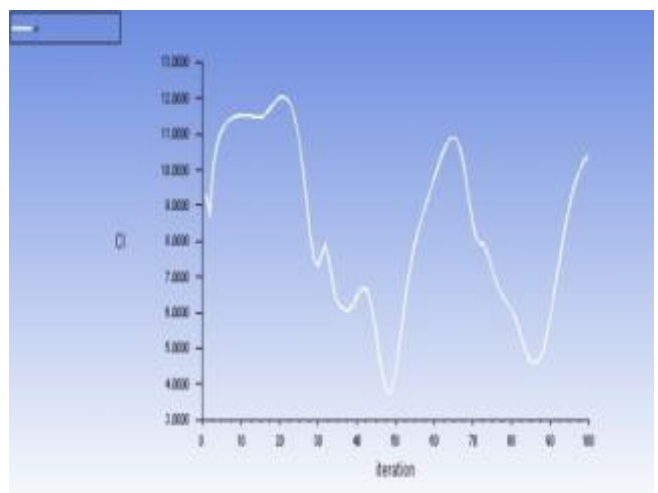

(a) $\mathrm{C}_{1}$ of corrugated profile

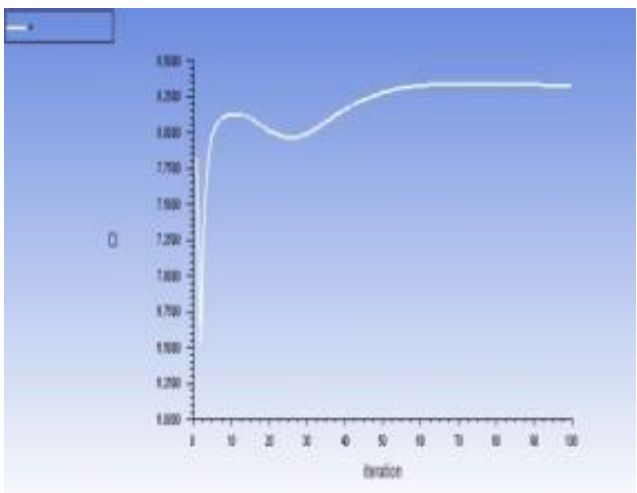

(b) $\mathrm{C}_{1}$ of NACA 0015 


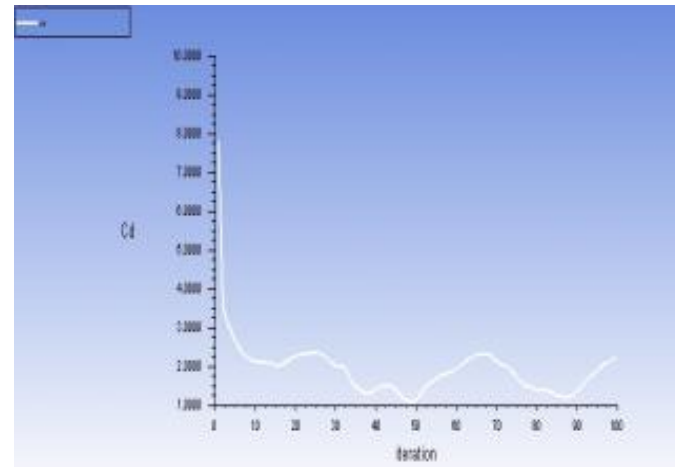

(c) $\mathrm{C}_{\mathrm{d}}$ of corrugated Profile

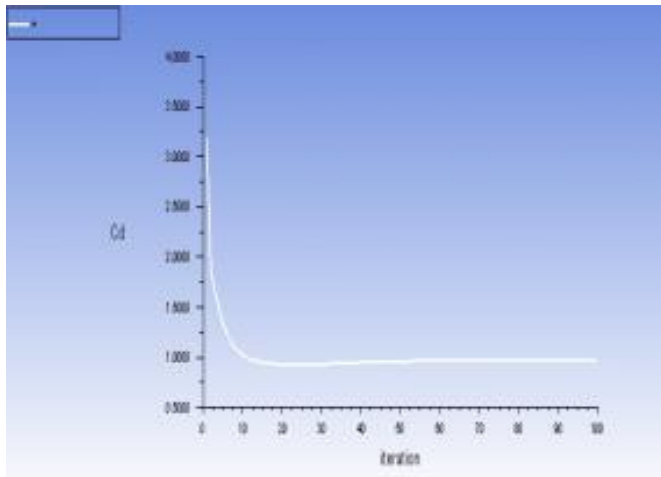

(d) $\mathrm{C}_{\mathrm{d}}$ of NACA 0015

\section{At 0-degrees AoA and $15 \mathrm{~m} / \mathrm{s}$ velocity}

The simulation is executed at a velocity of $15 \mathrm{~m} / \mathrm{s}$ with differing AoA from 0 degrees to 12 degrees, keeping the same boundary condition.

\section{Figure 11}

$C F D$ Results at $A o A=0$ (degrees) $(\operatorname{Re}=150000)$

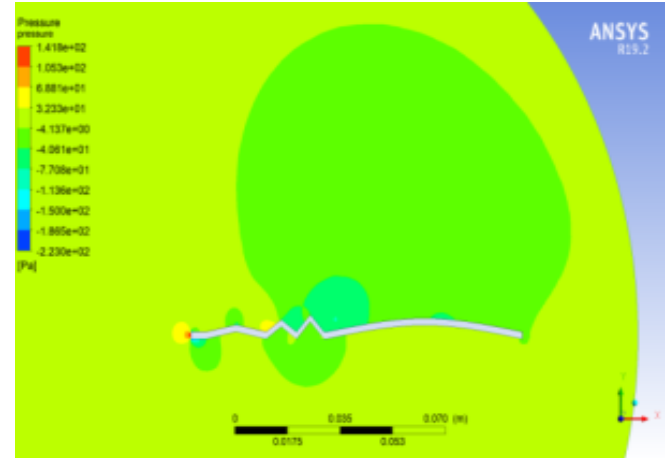

(a)Pressure plot of corrugated profile

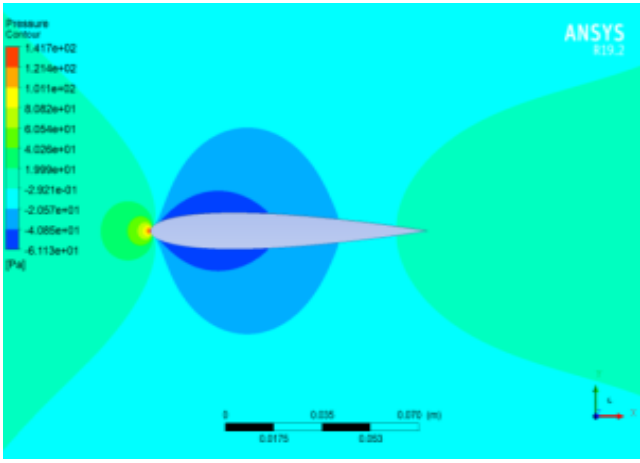

(b) Pressure plot of NACA 0015 


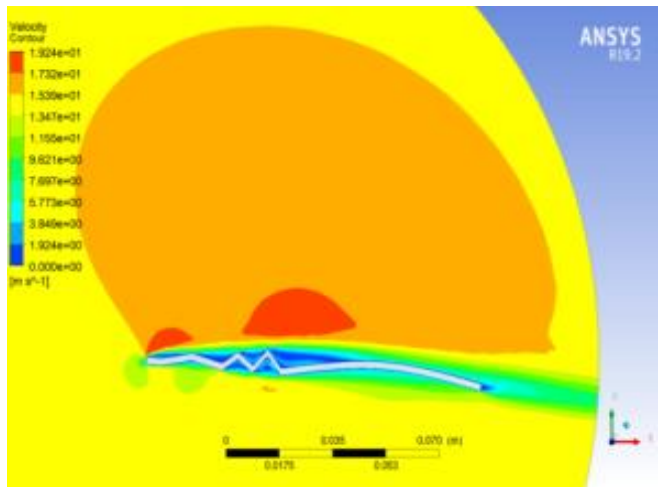

(c) Velocity plot of corrugated Profile

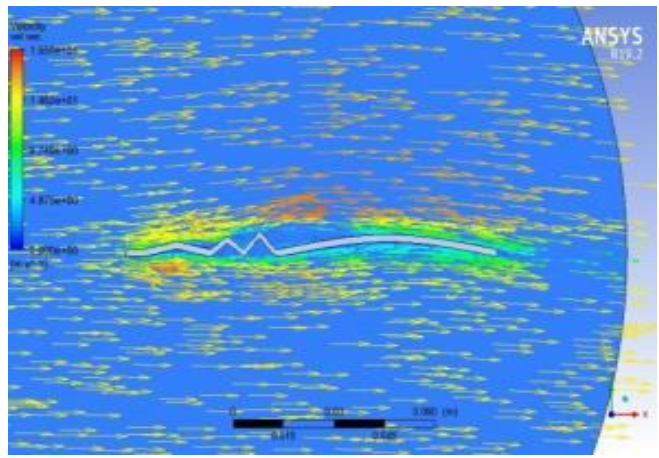

(e)Velocity vector of corrugated Profile

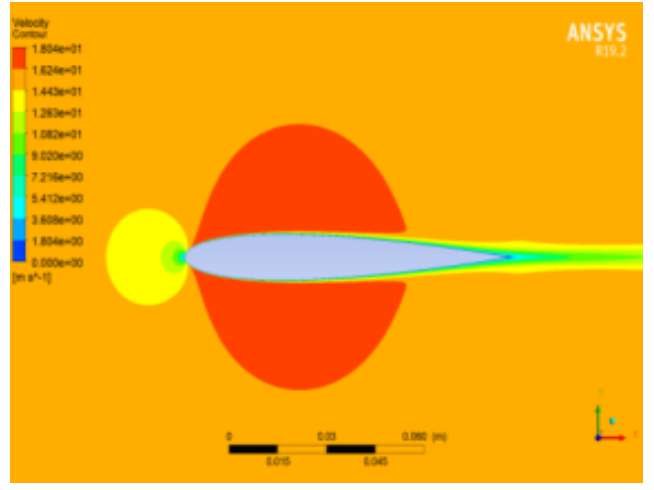

(d) velocity plot of NACA 0015

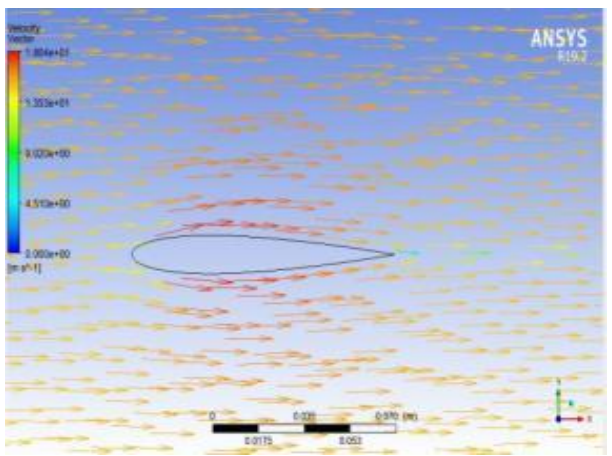

(f) Velocity vector of NACA 0015

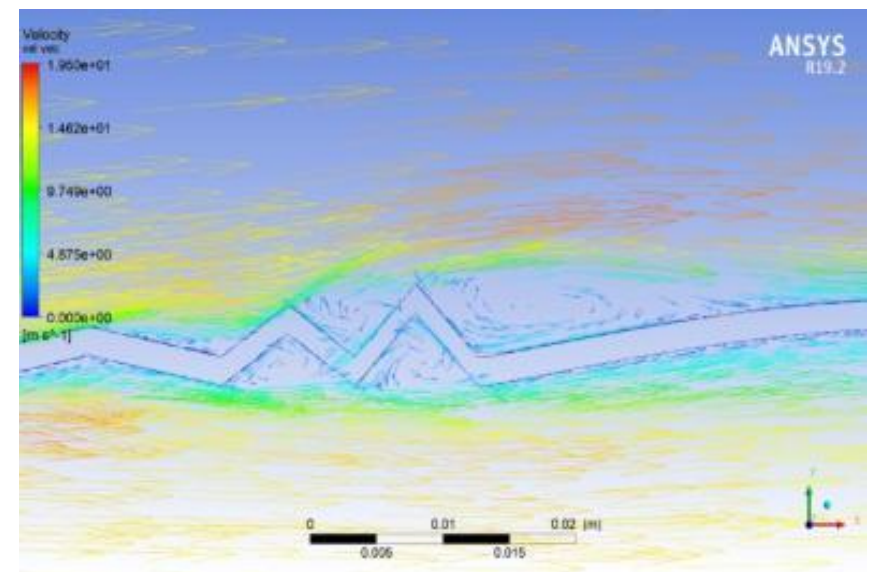

(g)Enlarged view of velocity vector showing trapped vortices in the valley

As the flow velocity increases from $10 \mathrm{~m} / \mathrm{s}$ to $15 \mathrm{~m} / \mathrm{s}$ the randomness, and the momentum of the flow particles also increases instantaneously. We can observe 
from Figures11(a), and 11(b) that the pressure on the pleated aerofoil goes on increasing at the leading edge at the stagnation point in comparison to the profiled aerofoil vice versa for velocity characteristics as represented in Figure 11(c) and 11(d). Since from Figures11(e) and 11(g) we can predict that as the velocity increases from $10 \mathrm{~m} / \mathrm{s}$ to $15 \mathrm{~m} / \mathrm{s}$ the flow is circulating inside the valleys. Flow reversal is taking place even at 0 -degrees AoA which is not at all happening in case of NACA 0015 as shown in Figure 11(f).

\section{Figure 12}

CFD Results at $A o A=4$ (degrees) $(R e=115000)$

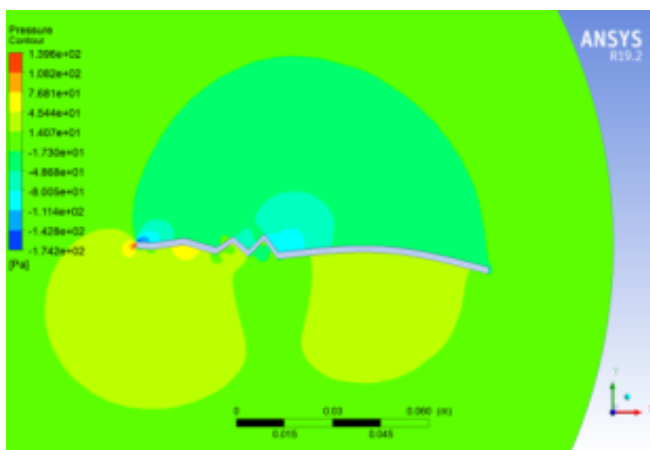

(a)Pressure of corrugated Profile

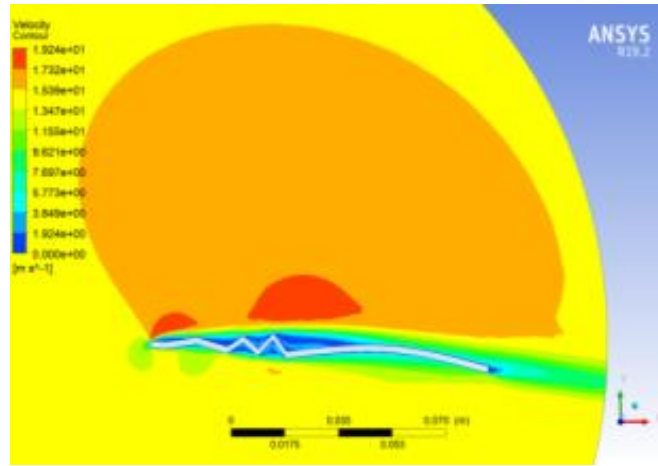

(c) Velocity of corrugated Profile

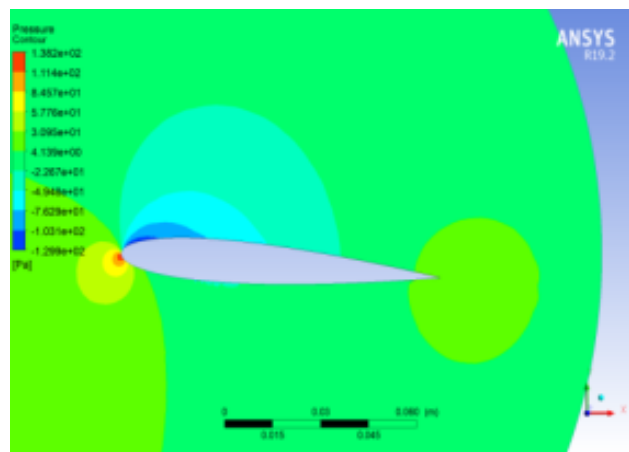

(b) Pressure of NACA 0015

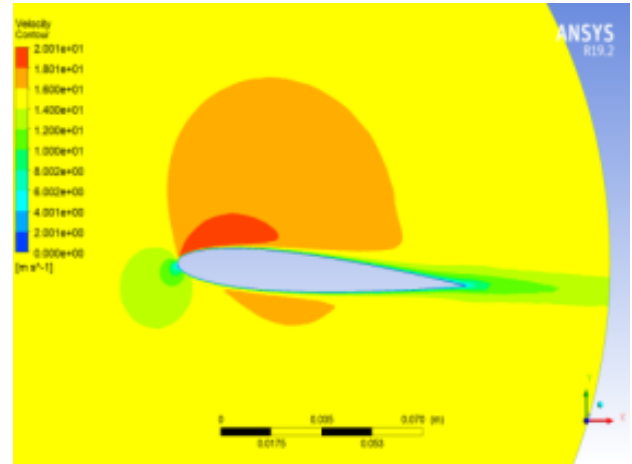

(d) Velocity of NACA 0015 


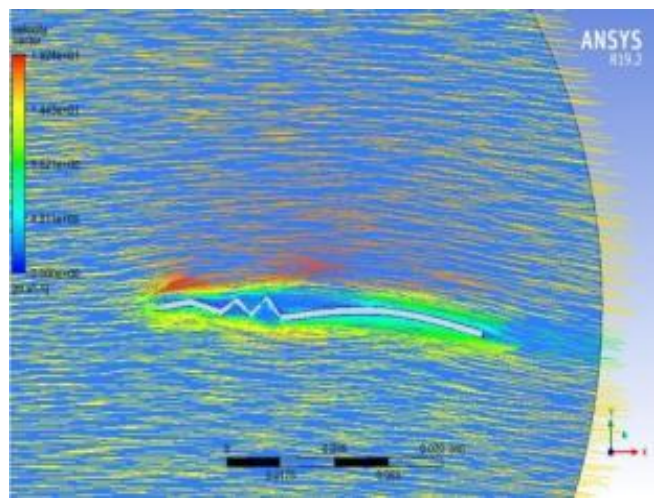

(e)Velocity vector of corrugated profile

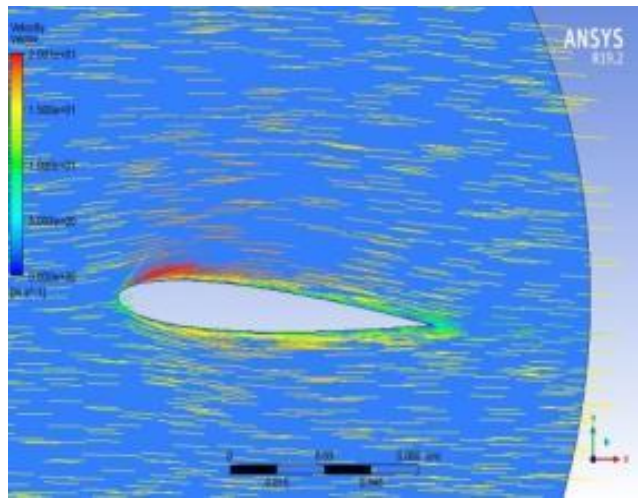

(f) Velocity vector of NACA 0015

\section{At 4-degrees AoA and $15 \mathrm{~m} / \mathrm{s}$ velocity}

At $\alpha=4^{\circ}$, the simulation shows that the pressure profile increases on the beneath the surface and reduces on the top portion side, as shown in Figures 12(a) and Figure 12 (b). The stagnation point shifts from the upstream leading edge to the downstream leading edge and zero velocity in the corrugated aerofoil valley, as shown in Figures 12(c). Figure12(e) shows more transition in the velocity vector and the intensity of the peak velocities also increases compared to profiled aerofoil, which is shown in Figure 12 (f).

\section{Figure 13}

CFD Results at $A o A=8($ degrees $)(\operatorname{Re}=115000)$

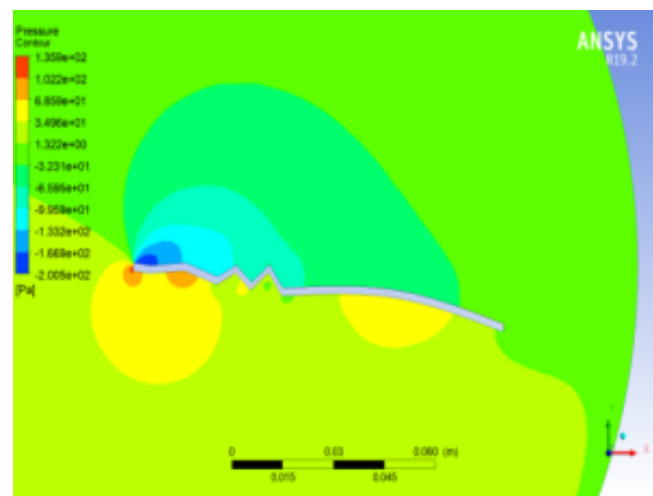

(a) Pressure of corrugated profile

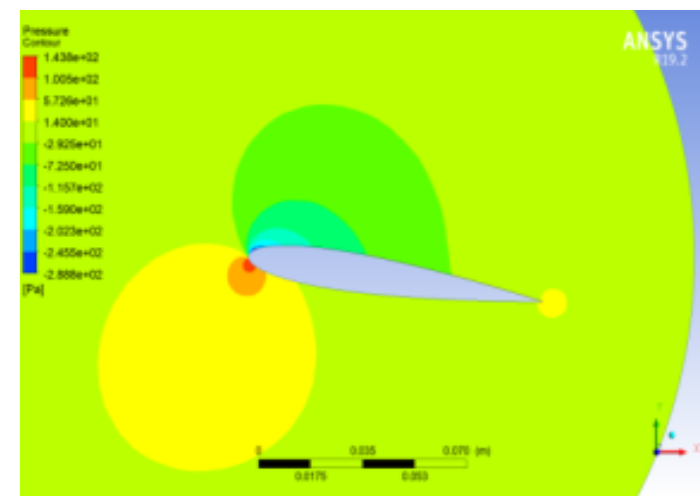

(b) Pressure of NACA 0015 


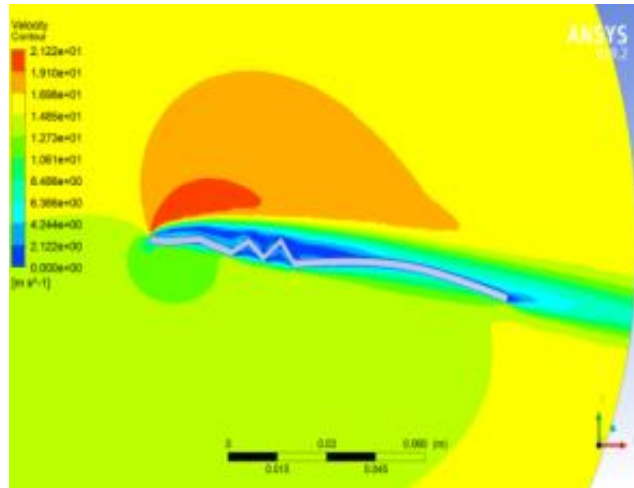

(c) Velocity plot of corrugated profile

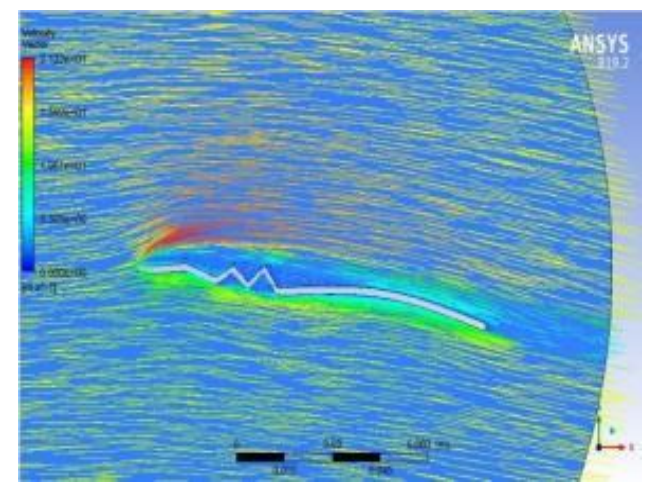

(e)Velocity vector of corrugated profile

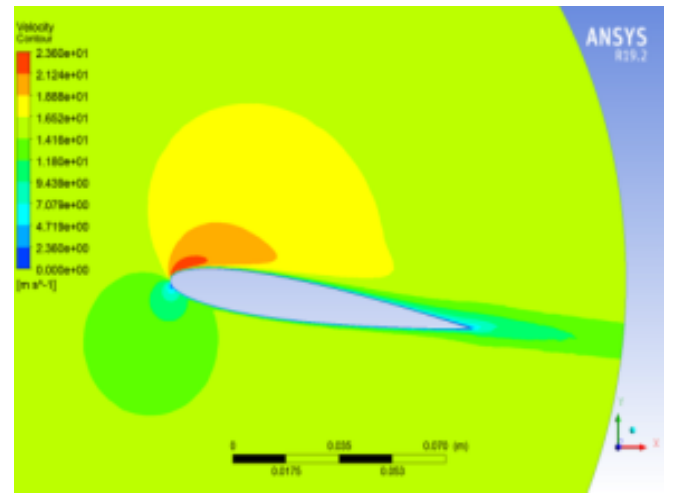

(d) Velocity of NACA 0015

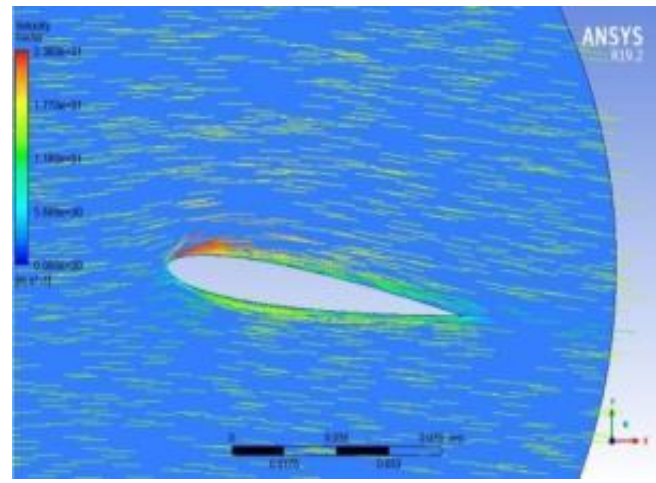

(f) Velocity vector of NACA 0015

\section{At 8-degrees AoA and $15 \mathrm{~m} / \mathrm{s}$ velocity}

From Figure 13 shows an increase in the angle of attack from $4^{\circ}$ to $8^{\circ}$; the corrugated aerofoil performs much better. After 8 degrees, the lift started decreasing, means stall initiated. The split flow requires a high-pressure retrieval when bubble is formed, the flow reattaches and this reattachment represents the transition -forcing mechanism. The stagnation point shifts to the bottom of the corrugated Profile, increasing the pressure difference, which mainly contributes to the lift production, as shown in Figure13(c) for pleated aerofoil and 13(d) profiled aerofoil. Near the sub-costa part which is nearly the $40 \%$ of the chord, the flow behaviour is much acquainted with the change in the angle of attack, and the upper surface attached flow is going to re-energize the reversed flow and delays separation as shown in Figure 13(e). In the next simulation phase or process, the angle of attack is increased from 8 degrees to 12 degrees to observe the change in aerodynamic lift coefficient and drag coefficient. 
International Journal of Aviation, Aeronautics, and Aerospace, Vol. 8 [2021], Iss. 2, Art. 3

Figure 14

CFD Results at $A o A=12($ degrees $)(\operatorname{Re}=115000)$

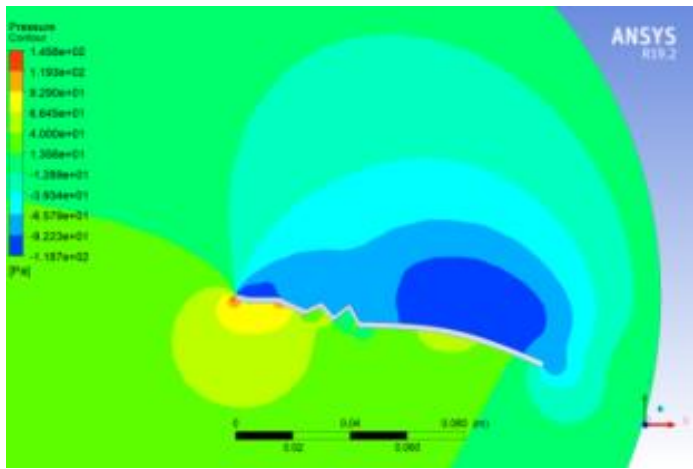

(a)Pressure of corrugated Profile

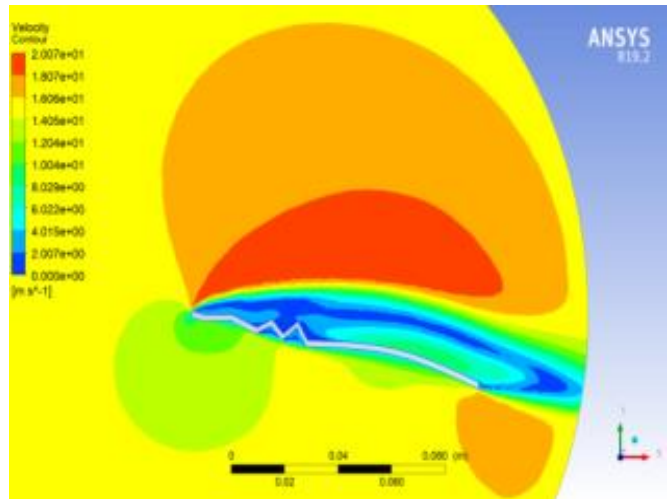

(c) Velocity of corrugated aerofoil

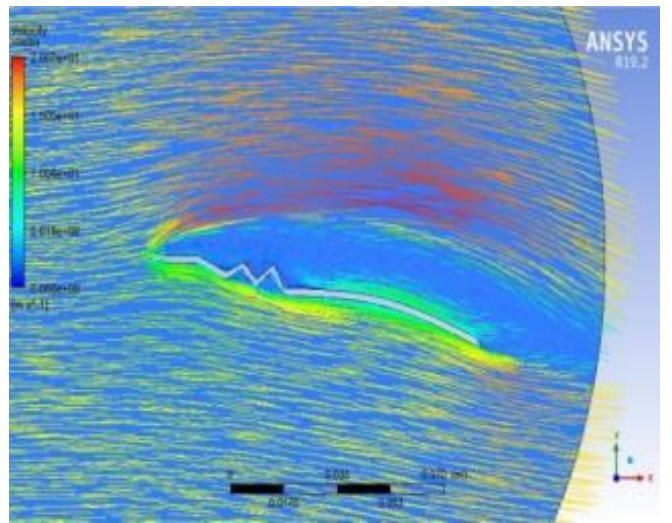

(e)Velocity vector of corrugated Profile

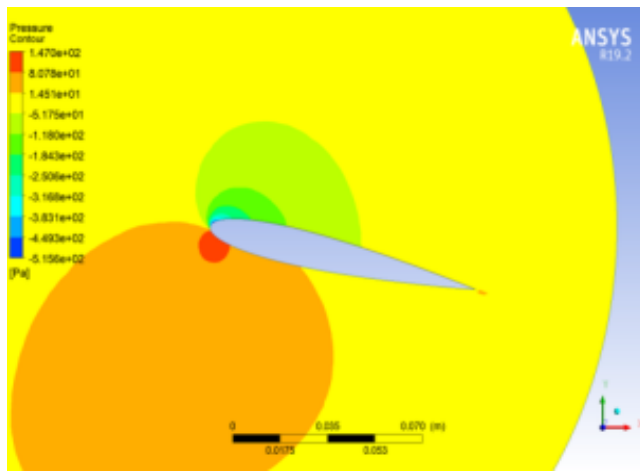

(b) Pressure of NACA 0015

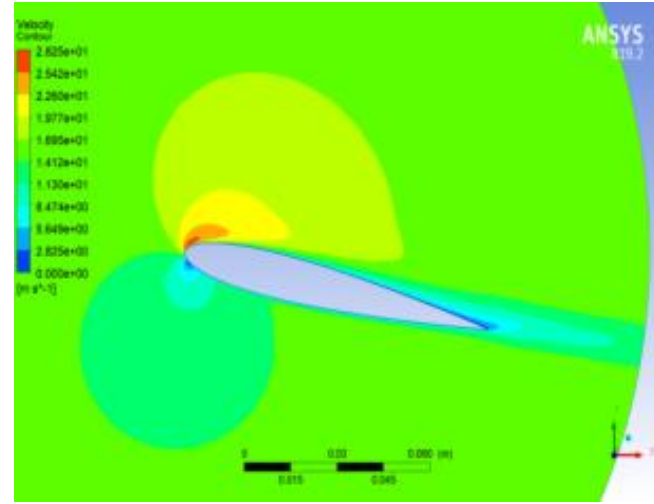

(d) Velocity of NACA 0015

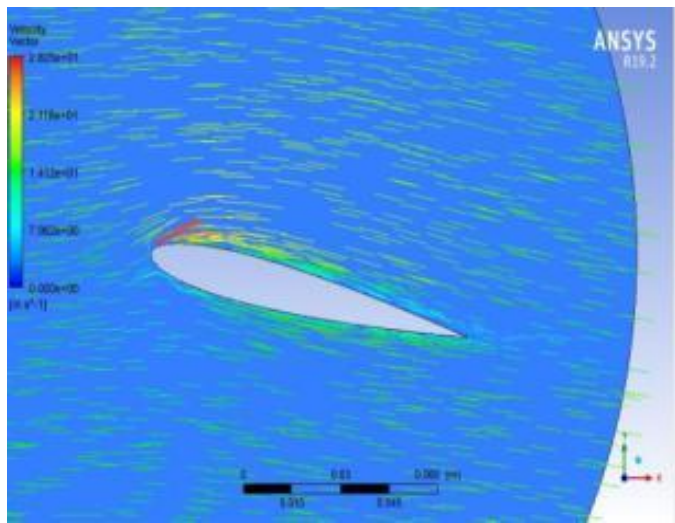

(f) Velocity vector of NACA 0015 


\section{At 12-degrees AoA and $15 \mathrm{~m} / \mathrm{s}$ velocity}

From Figure14, we can predict that as the AoA is increased to 12 degrees, the stagnation point shifted beneath the crest of the corrugated aerofoil causes flow circulation and swirl on the top face of the pleated aerofoil and large eddies on the traditional NACA 0015 aerofoil, the flow separation at the upstream and the boundary layer also progresses much faster, and the pressure is almost zero on the camber of the trailing edge profile, as shown in Figure14(a).With increase in angle of attack, we can observe that the flow is separated at the leading edge and circulation zone is created on the upper surface of the pleated aerofoil resulting in the formation of eddies and vortices.

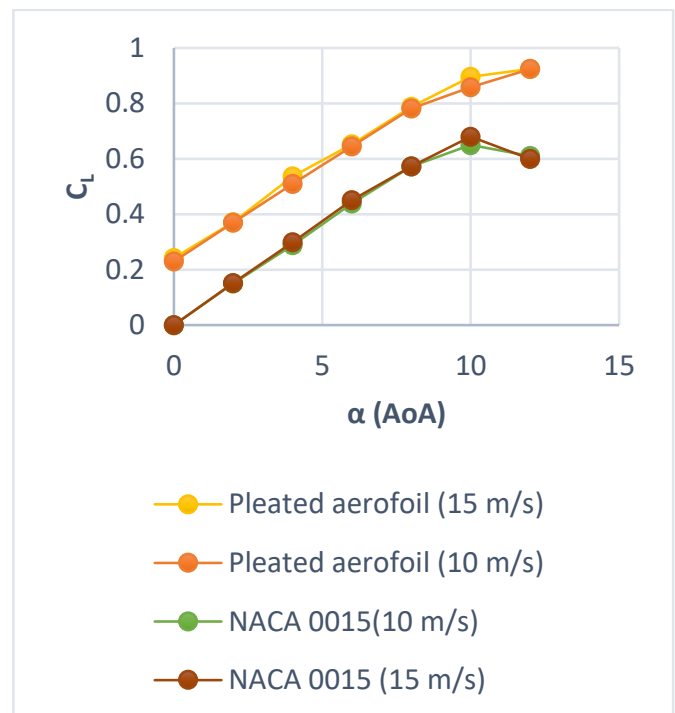

Figure $15 C_{L}$ vs AoA

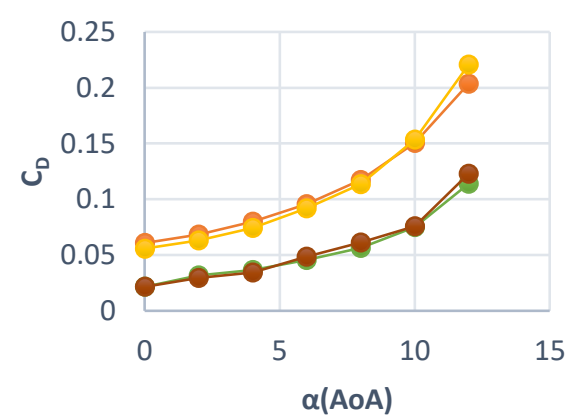

$$
\begin{aligned}
& \text { - Pleated aerofoil }(10 \mathrm{~m} / \mathrm{s}) \\
& \text { - Pleated aerofoil }(15 \mathrm{~m} / \mathrm{s}) \\
& - \text { NACA } 0015(10 \mathrm{~m} / \mathrm{s}) \\
& - \text { NACA } 0015(15 \mathrm{~m} / \mathrm{s})
\end{aligned}
$$

Figure $16 \mathrm{C}_{D}$ vs $\mathrm{AoA}$ 


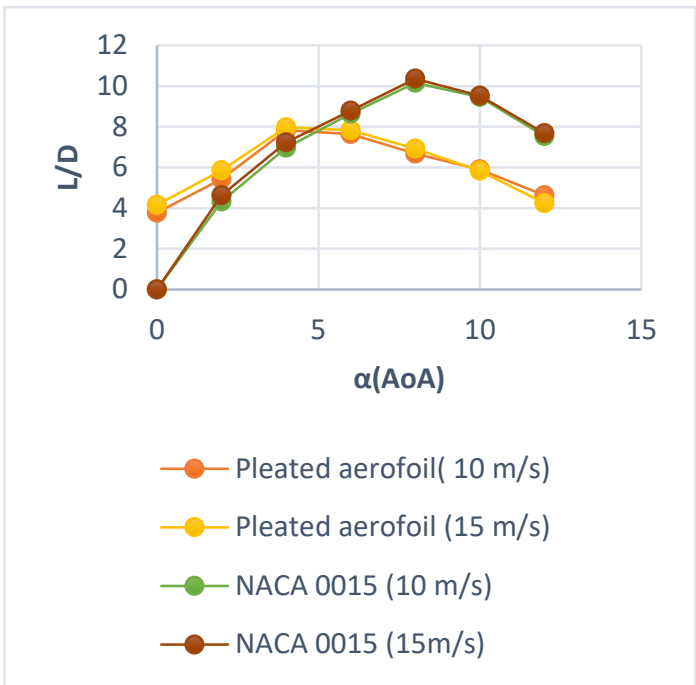

Figure $17 \mathrm{~L} / \mathrm{D}$ vs AoA

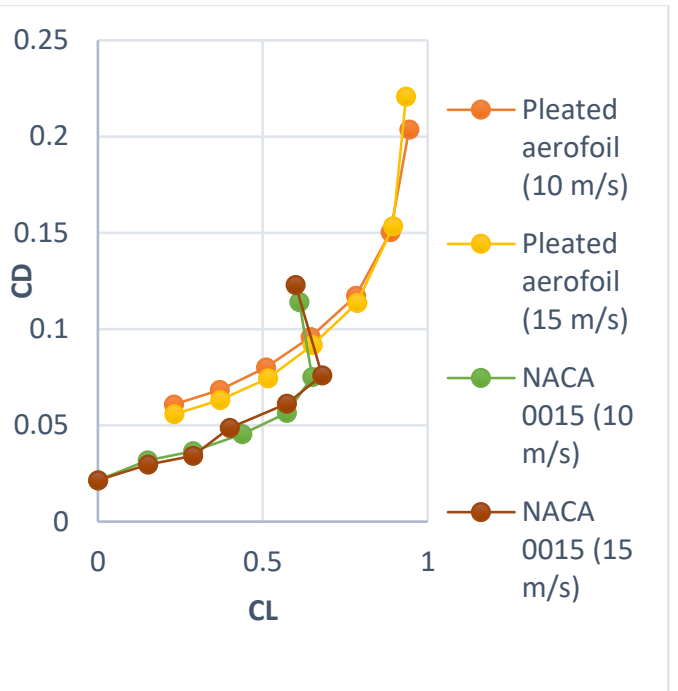

Figure $18 C_{D}$ vs $C_{L}$

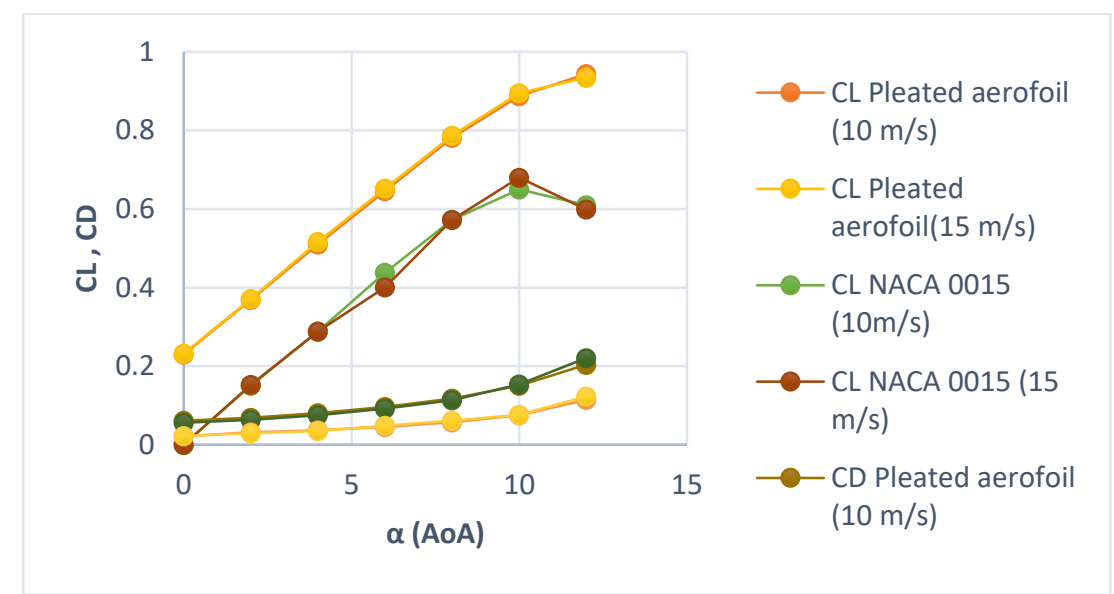

Figure $19 C_{D}, C_{L}$ vs AoA

From the above Figure15, we can observe that the coefficient of lift of corrugated aerofoil is much higher than conventional aerofoil and increasing with an increase in the angle of attack. From Figure 16, we can say that the coefficient of drag of Pleated corrugated aerofoil is also increasing with the change in angle of attack, in contrast, to increase in the lift coefficient. Figure17 represents the variation of gliding ratio (L/D) concerning the angle of attack. We can see that the gliding ratio of the pleated corrugated aerofoil is higher at 4 degrees and decreases at higher angle as compared to traditional NACA 0015 aerofoil, which is the subject of interest because if the gliding ratio is higher, it means that the aerodynamic performance of the pleated aerofoil is much better compared to other Profile. But 
the vital thing to note down is that Pleated aerofoil's performance starts decreasing at a higher angle of attack at high Reynolds number. It means that pleated corrugated aerofoil is best suited for low Reynolds number flyer. Figure 18 shows the drag polar curve, which is the graph between the drag and coefficients of lift and mainly talks about the effect of profile drag and induced drag on the corrugated structure's shape. Figure 19 shows the variation of $C_{L}, C_{D}$ with respect to the angle of attack in a single curve which tells about the given Profile's performance.

\section{Conclusions}

The concluding remarks are to understand the outcome of performance parameters of the bio-mimicked corrugated dragonfly wing cross-section and conventional NACA0012 aerofoil at two different Reynolds numbers of 75000 and 115000. The CFD simulation prediction is that the pleated corrugated profile performance is much better than smooth aerofoil at all angle of attack. The corrugated aerofoil lift-to-drag ratio is higher in between 4 degrees to 8 degrees and has a maximum gliding ratio that is high compared to the traditional aerofoil model studied here. The pleated aerofoil design used, bio-mimicked from 'Pantalaflavescens' offers considerably superior and compatible results at the $40 \%$ of the forewing chord. Eventually, we noticed that the CFD analysis solution provides more insight into the aerodynamic behaviour of the corrugated wing structure and tells us that the natural design specification plays a vital role in reducing the formation of wake due to flow breakdown (i.e., adverse pressure gradient) leads to recirculation zone inside the $\mathrm{V}$-shaped grooves and the flow reattaches to the edge of next corrugation. Ultimately, concluded that the pleated structure of dragonfly wing yields better aerodynamic performance at low Reynolds number, i.e., high $\mathrm{L} / \mathrm{D}$ ratio and do a favor in decrement of shear drag which is mostly required for lightweight and structurally stable MAVs and UAVs. 


\section{References}

Barnes, C., \& Visbal, M. (2013). Numerical exploration of the origin of aerodynamic enhancements in low- Reynolds number corrugated airfoils, Physics of Fluids, 25(11). https://doi.org/10.1063/1.4832655

Broering, T. M., \& Lian, Y. (2012). The effect of phase angle and wing spacing on tandem flapping wings. Acta Mechanica Sinica, (6), 1557-1571.

Chen, Y. H., \& Skote, M. (2016). Gliding performance of 3-D corrugated dragonfly wing with a spanwise variation. Journal of Fluids and Structures, 62, 1-13.

Fish, F. E., Weber, P. W., Murray M. W., \& Howle, L. E. (2011). The tubercles on Humpback whales' flippers: Application of bio-inspired technology. Integrative and Comparative Biology, 51(1), 203-213.

Fish, P. E. (2006). Limits of nature and advances of technology in marine systems: What does biomimetics have to offer to aquatic robots? Applied Bionics and Biomechanics, 3(1), 49-60.

Gao, H., Hu, H., \& Wang, Z. J. (2008). Computational study of unsteady flows around dragonfly and smooth airfoils at low Reynolds numbers. In 46th AIAA Aerospace Sciences Meeting and Exhibit, Reno, NV.

Ho, W. H., \& New, T. H. (2016). Unsteady numerical investigation of two different corrugated airfoils. Proceedings of IMechE Part G - Journal of Aerospace Engineering. https://doi.org/10.1177/0954410016682539

Hu, H., \& Tamai, M. (2008). Bioinspired corrugated airfoil at low Reynolds numbers. Journal of Aircraft, 45(6), 2068-2077.

Kesel, A. B. (2000). Aerodynamic characteristics of dragonfly wing sections compared with technical aerofoils. Journal of Experimental Biology, 203, 3125-3135.

Khan, M. A., \& Padhy, C. (2020). Aerodynamic and experimental analysis of biomimic corrugated dragonfly aerofoil. INCAS Bulletin, 12(2), 73-85. doi:10.13111/2066-8201.2020.12.2.7

Khan, M. A., \& Padhy, C. (2019). Aerodynamic and structural analysis of biomimetic corrugated wing. Fluid Mechanics Research International Journal, 3(2), 61-67. doi:10.15406/fmrij.2019.03.00053

Khan, M. A., \& Padhy, C. (2021). Influence of aerodynamic parameters on dragonfly inspired corrugated aerofoil. In: K. B. Rushi, R. Sivaraj, and J. Prakash (eds), Advances in Fluid Dynamics. Lecture Notes in Mechanical Engineering. Springer. https://doi.org/10.1007/978-981-15-4308-1_23

Khan, M. A., Padhy, C., Nandish, H. M., \& Rita, K. (2018). Computational analysis of bio-inspired corrugated airfoil with varying corrugation angle. Journal of Aeronautics \& Aerospace Engineering, 7, 208. doi:10.4172/2168-9792

Levy, D. E., \& Seifert, A. (2009). Simplified dragonfly airfoil aerodynamics at Reynolds numbers below 8000. Physics of Fluids, 21, 071901. https://doi.org/10.1063/1.3166867 
Liu, H., Ellington, C. P., Kawachi, K., Van Den Berg, C., \& Willmott, A. P. (1998). A computational fluid dynamic study of hawkmoth hovering. Journal of Experimental Biology, 201, 461-477.

Lu, K., Xie, Y. H., Zhang, D., \& Lan, J. B. (2013). Numerical investigations into the asymmetric effects on the aerodynamic response of a pitching airfoil. Journal of Fluids and Structures, 39, 76-86.

Menter, F. R. (2012). Best practice: Scale-resolving simulations in ANSYS CFD version 1.02. https://cfd.grs.de/downloads/best-practice_srs_menter2012.pdf

Menter, F. R., \& Egorov, Y (2010). Scale-adaptive simulation method for unsteady flow predictions part 1: Theory and model description. Flow, Turbulence and Combustion, 85(1), 113- 138.

Mingallon, M., \& Ramaswamy, S. (2011). The architecture of the dragonfly wing: A study of the structural and fluid dynamic capabilities of the anisoptera's forewing. In Proceedings of the ASME 2011 International Mechanical Engineering Congress \& Exposition (IMECE2011).

Murphy, J., \& Hu, H. (2009). An experimental investigation on a bio-inspired corrugated airfoil. In 47th AIAA Aerospace Sciences Meeting and Exhibit, Orlando, FL.

Murphy, J., \& Hu, H. (2010). An experimental study of a bio-inspired corrugated airfoil for micro air vehicle applications. Experiments in Fluids, 49(2), 531546.

Norberg R. A. (1975) Hovering flight of the dragonfly Aeschna Juncea L., kinematics and aerodynamics. In T. Wu, C. J. Brokaw, and C. Brennen, (eds) Swimming and Flying in Nature. https://doi.org/10.1007/978-1-47571326-8_19

Okamoto, M., Yasuda, K., \& Azuma, A. (1996). Aerodynamic characteristics of the wings and body of a dragonfly. Journal of Experimental Biology, 199, 281-294.

Rees, C. J. (1975a). Aerodynamic properties of an insect wing section and a smooth aerofoil compared. Nature, 258, 141-142.

Tamai, M., Wang, Z., Rajagopalan, G., Hu, H., \& He, G. (2007). Aerodynamic performance of a corrugated dragonfly airfoil compared with smooth airfoils at low Reynolds numbers. 45th AIAA Aerospace Sciences Meeting and Exhibit. https://doi.org/10.2514/6.2007-483

Taylor, G. K., Nudds, R. L., \& Thomas, A L. R. (2003). Flying and swimming animals cruise at a Strouhal number tuned for high power efficiency. Nature, 425, 707-711.

Vargas, A. (2006). Numerical investigation of the aerodynamic characteristics of a dragonfly wing section [unpublished doctoral dissertation]. The George Washington University. 
Vargas, A., Mittal, R., \& Dong, H. (2008). A computational study of the aerodynamic performance of a dragonfly wing section in gliding flight. Bioinspiration \& Biomimetics, 3(2), 026004. doi:10.1088/17483182/3/2/026004

Wakeling, J. M., \& Ellington, C. P. (1997). Dragonfly flight II velocities, accelerations and kinematics of flapping flight. Journal of Experimental Biology, 200, 557-582.

Wakeling, J. M., \& Ellington, C. P. (1997). Dragonfly flight III lift and power requirements. Journal of Experimental Biology, 200, 583-600.

Wakeling, J. M., \& Ellington, C.P. (1997). Dragonfly flight I gliding flight and steady-state aerodynamics. Journal of Experimental Biology, 200, 543-556.

Zhou, Z., Li, C., Nie, J. B., \&Chen, Y., (2013). Effect of oscillation frequency on wind turbine airfoil dynamic stall. Materials Science and Engineering, 52, $1-5$. 